Yüzüncü Y1l Üniversitesi
Tarim Bilimleri Dergisi

Araştırma Makalesi (Research Article)

\title{
Muş Salebinin Menşei ve Muş Civarının Orkideleri
}

\author{
Sinan İŞLER ${ }^{1}$, Ekrem SEZİK ${ }^{2}$ \\ ${ }^{1}$ Yuzuncu Y1l Üniversitesi, Eğitim Fakültesi, Mat. ve Fen Bil. Eğit. Böl., 65080 Van, Türkiye \\ ${ }^{2}$ Yeditepe Üniversitesi, Eczacilık Fakültesi, Farmakognozi Bölümü, İstanbul, Türkiye \\ *Sorumlu yazar e-posta: sinan_1970@hotmail.com
}

\section{Makale Bilgileri}

Geliș: 17.05.2019

Kabul: 02.09.2019

Online Yayınlanma 30.09.2019

DOI: $10.29133 /$ yyutbd.567181

\section{Anahtar kelimeler}

Flora,

Muş,

Orkideler,

Salep,

Türkiye.
Öz: Muş ilinde Hasköy ilçesi Altınova Beldesi civarı ve Bulanık ilçesi civarında salep elde edilişi, elde edilişte kullanılan türler, yöntemleri araştırma amacımızı teşkil etmiştir. Yapılan araştırmalar sonucunda Muş Hasköy ilçesi Altınova Beldesi civarı ve Bulanık ilçesi civarı olmak üzere iki merkezde salep elde edilmektedir. Ayrıca Diyarbakır'da da salep toplandığı araştırmalarımız sonucu ortaya çıkmıștır. Bu merkezlerde salep elde etme yöntemleri ve salep elde etmede kullanılan orkide türleri tespit edilmiştir. Muş Hasköy ilçesi Altınova Beldesi civarı ve Bulanık ilçesi civarında salep karışımındaki parçalı yumrular Dactylorhiza umbrosa, Dactylorhiza iberica'ya aittir. Yuvarlak olanlar ise Anacamptis palustris, Orchis pseudolaxiflora, Anacamptis coriophora olup, ikisi rizomlu olmak üzere 4 cinse ait 7 orkide türü tespit edilmiştir. Salep elde etmek amacıyla her yıl milyonlarca orkide tahrip edilmektedir. Bu tahribat çayır salebi elde edilen orkide türlerini tehlikeye sokmaktadır.

\section{The Origin of Muş Salep and Orchids the Vicinity of Muş}

\section{Article Info}

Received: 17.05 .2019

Accepted: 02.09.2019

Online Published 30.09.2019

DOI: 10.29133/yyutbd.567181

Keywords

Flora,

Muş,

Orchids,

Salep,

Turkey.

\begin{abstract}
Our aim is to clarify the species used for production of salep, production methods of orchids in Altınova region of Haskoy and Bulanık districts of Muş province. The orchids species were collected from Muş province, Hasköy district around Altınova town and around Bulanık district. Moreover, our research showed that salep is collected from Diyarbakır as well. The methods and the species used to obtain salep in these areas were determined. Segmentary tubers collected from Muş province, Hasköy district around Altınova town and around Bulanık district belong to Dactylorhiza umbrosa, Dactylorhiza iberica. As for The round tubers, they are Anacamptis palustris, Orchis pseudolaxiflora, Anacamptis coriophora. In the area, 7 orchids species were determined. The species belong to 4 orchids genera. Two of the species are rhizomatous. Every year millions of orchids are being destructed to obtain salep. This destruction especially endangers the salep species growing in meadows.
\end{abstract}

\section{Giriş}

Dünya üzerinde 880 cins ve 21 000-26 000 kadar orkide türü bulunan Orchidaceae familyas üzerinde günümüze kadar özellikle taksonomik, filogenik ve korolojik çalışmalar yapılmıştır (Stevens, 2008). Türkiye orta kuşak orkideleri bakımından zengin ülkelerden biridir. Son yapılan araştırmalara göre orkideler Türkiye'de 191 takson ile temsil edilmektedir (Petrou ve ark., 2016). Belirtilen orkidelerden 120 kadarı salep elde edilişinde kullanılmaktadır. Anadolu'da Orchis, Ophrys, Serapias, 
Himantoglossum, Comperia, Anacamptis, Barlia, Aceras, ve Neotinea cinslerine ait 117 türün salep elde edilişinde kullanıldığı tespit edilmiştir (Sezik, 2002a,b). Ülkemizdeki Orchidaceae taksonlarının sayısı Boissier'e (1884) göre 15 cins ve 60 tür; Schlechter'e (1928) göre 19 cins ve 69 tür; Renz ve Taubenheim’e (1984) göre 24 cinse ait 93 tür (32 alttür), Sezik’e (1967) ve Sezik’e (1969a) göre 18 cins ve 91 tür; Sezik'e göre (1982) 24 cins 90 türdür. Son yayın ve çalışmalar göz önüne alındığında Türkiye'de 24 cins ve 100 tür (alt türler bu sayıya dahil değildir) vardır (Sezik, 1984). Ancak Kreutz ise 24 cins 148 tür (Kreutz, 1998), Orchidaceae familyasına 9 cinse ait 46 tür ilâve etmiştir (Kreutz, 2000), (Geylan, 2017). Bu eserlerin hiçbirinde Muş ve civarının orkideleri doğrudan incelenmemiş; ya dağılış şeklinde bildirilmiş ya da dăğlış haritalarında Muş ve civarında bulunan türler gösterilmiştir.

Yumrulu karasal orkide türlerinden salep adı verilen drog elde edilmektedir. Salep piyasada Kastamonu, Muğla, Antalya, Silifke, K. Maraş, Van Salebi gibi değişik ticari isimler altında bulunmaktadır. Bunlardan Muğla, Kastamonu, K. Maraş ve Van salepleri ve hangi orkide türlerinin bu saleplerin elde edilişinde kullanıldığı ayrıntılı bir şekilde araştırılmıştır (Baytop ve Sezik, 1968; Sezik ve Özer, 1983; Sezik ve Baykal, 1988; Sezik ve Baykal, 1991; Sezik, 2002a,b; İşler, 2005). Muş salebi ile ilgili ise Sezik' in ilk yayınlarının dışında herhangi bir yayın bulunmamaktadır (Baytop ve Sezik, 1968; Sezik, 1984). Diğer taraftan son yıllarda Muş bölgesinden piyasaya çıkan salep miktarı yüksek miktarlara ulaşmıştır. Orta kuşak orkideleri koruma altında olan bitkilerdir. "Red Data Book" ta kayitlidır (Ekim ve ark., 2000).

Ülkemizde ve bölgemizde salep üretiminin artması, yumrulu orkidelerin tahribinin inanılmaz boyutlara yükselmesine sebep olmaktadır. Salep elde edilmesi en az 40 milyon orkidenin tahribine yol açmaktadır (Sezik, 2002a). Dolayısıyla, ülkemiz ve çevremiz için önemli bir çevre ve tabiat tahribi problemi ortaya çıkmaktadır. Salep bitkilerinin hemen hepsi belirli yasalarla koruma altına alınmasına rağmen salep orkideleri henüz çiçekte iken yumruları kullanılmak üzere topraktan sökülmektedir.

Salep orkidesinin toprak altında bulunan iki yumrusundan sadece yan yumrunun alınması doğru iken toplayıcılar bunu bilmedikleri için genellikle her iki yumruyu da almaktadırlar. Toplanan yumrular suyla iyice yıkanarak temizlenir, ipe dizilir ve su veya sütle kaynatılıp, açık havada kurutulur. Yumrular kurutulduktan sonra en fazla $3 \mathrm{~cm}$ uzunluğunda ve 2 gr. ağırlığında kalırlar. Kuruyan yumrulardan dövülerek elde edilen ögütülmüş materyal, kullanıma hazır saleptir. Bir kilo salep için 1000 ile 4000 yumru kullanılmaktadır. Ülkemizde yılda 45 ton salep üretildiği varsayılmakta olup, bu da topraktan bir y1lda sökülen 45-180 milyon salep orkidesi yumrusu demektir (Erdem, 2004).

Yukarıda kısaca özetlenen durum göz önüne alınarak doğu salebinin elde edildiği Muş ilinde salep elde edilişi, elde edilişte kullanılan türler, yöntemleri ve bunun yanında bölgede bulunan orkideler, yayılışları, tahrip edilen orkideler araştırma amacımızı teşkil etmiştir. Çalışmamız bunlarla ilgili bilgilerin ortaya koyulmasına yönelik olarak planlanmış ve yapılmıştır.

\section{Salep Elde Edilen Orkide Türleri}

Ticari saleplerin elde edilişinde kullanılan orkide türleri aşağıda, salep kazıcılarının (toplayıcılarının) tercih sırasına göre, çizelgeler halinde sunulmuştur (Çizelge 1).

\section{Salebin Kimyasal Yapısı}

Ülkemizde mevcut olan ticari saleplerin yapısında glikomannanlar (\% 11-44), nişasta (\% 8-19), redüktör ozlar (\% 2-3) ve proteik yapıdaki maddeler (\% 1) bulunmaktadır. Etkili madde veya salebin kullanılma sebebi olan madde glikomannanlardır. Glikomannan, süt ve su ile şişer ve akıcı bir çözelti meydana getirir. Kaliteli bir salep \% 40 civarında glikomannan taşır. Yediğimiz Maraş dondurmasına geç erime ve sertlik, içtiğimiz salebe kıvam veren glikomannanlar'dır. Salepte bulunan az miktardaki nişasta da şişme yeteneğinden dolayı glikomannanlara yardımcı olmaktadır (Sezik, 1967; 1984).

\section{Salebin Kullanılıșı}

İbn-i Sina salebin afrodizyak, balgam artırıcı, iştah açıcı, felç giderici olarak kullanılmasını tavsiye etmekte ise de (Sezik, 1967), artık bu amaçlarla kullanılmamaktadır. Sadece kışın içilen sütlü salep ve dondurmanın yapısına girmesiyle ekonomik bir değere sahiptir. 


\title{
Orkidelerin Tahribi
}

Ülkemizde orkidelerin tahribinin en önemli sebebi yüksek oranda yumruları ile üreyen (çoğalan) orkidelerin, salep elde edilmek üzere yumrularının kazılarak alınmasıdır. Bitkiler ya çiçek açmadan veya çiçekli iken toplanmakta, yumrusu alındıktan sonra bir kenara atılmaktadır. Yani gelişme devam etmemekte, tohum meydana gelmemekte ve ferdin hayatı son bulmaktadır. Orkideler, yumruları ile de ürerler. Ama yumrular alındığı için, bu imkân da ortadan kalkmış olmaktadır. Tohumlardan üreme de zordur. Çünkü tohumlar toprakta bulunan Rhizoctonia vb mikrofunguslarla bir müşterek hayat sonucu protokorm meydana getirmekte, bu yapı da 2-15 yıl içinde bitkiyi verebilmektedir. Bu süre zarfinda, protokormun değişen çevre şartlarından çok etkileneceği kaçınılmazdır.

\section{Orkidelerin Tehlike Kategorileri}

Ekim ve ark. (2000) tarafından yayınlanmış olan Türkiye Bitkileri Kırmızı Kitabında "Red Data Book" kitabında Türkiye orkideleri ve "Van ve Çevresi Geofitleri Üzerinde Floristik Bir Araştırma" ile ilgili kayıtlar aşağıda verilmiştir (Ekim ve ark., 2000). Türkiye" de doğal olarak yetişen 150 civarındaki orkide türünün önemli bir kısmı (\%85) yumruludur. Yumrulu orkidelerin çoğundan salep elde edilişinde yararlanılmaktadır. Çalışmamızda daha önce salepleri araştırılmamış olan Van Bölgesi, bunun yanında yeni bölgelerden Akdağ Madeni bölgeleri elde etmede kullanılan türler ve yöntemleri açısından araştırılmıştır. Araştırmamız sonucu daha önce salep elde edilmeyen Çeşme-Karaburun, BalıkesirYenice, Kütahya-Simav, Eskişehir- Bilecik, Bartın, Tokat, Samsun-Alaçam, Giresun, Ordu-Bulancak, Ünye, Sivas-Yıldızeli civarında da salep elde edilmeye başlandığı tespit edilmiştir. Araştırmalarımız salep ticaretinin ve ticaret merkezinin Siirt'e kaydığını ortaya çıkarmıştır. Halen ticaret merkezleri olarak Siirt ve Bucak kabul edilmektedir. Doğu Anadolu'da salep üretimi artmış ayrıca bu bölgeye Kuzey Irak ve İran'dan kaçak olarak tonlarla ifade edilen miktarlarda salep getirilmiş ve halende getirilmektedir. Bunun yanında, Batı Anadolu'da, salep ticaretinin önemli bir kısmı Güneydoğu Anadolu'dan ve bilhassa Siirt civarından gidip yerleşenler tarafından yapılmaktadır.

Çizelge 2. Türkiye'de tehlike altında olan endemik orkideler (Ekim ve ark., 2000).

\begin{tabular}{lll}
\hline 1 & Cephalanthera kotschyana Renz \& Taub & LR(lc) \\
2 & Dactylorhiza chuhensis Renz \& Taub & LR(cd) \\
3 & Dactylorhiza nieschalkiorum H. Baumann \& Künkele & LR(lc) \\
4 & Dactylorhiza osmanica (KL.) Soó var anatolica (Nelson) Renz \& Taub & LR(nt) \\
5 & Dactylorhiza osmanica (KL.) Soó var osmanica (Nelson) Renz \& Taub & LR(lc) \\
6 & Epipactis pontica Taub. & LR(lc) \\
7 & Ophrys burnmuelleri M. Schulze ex Bornm.subsp carduchorum Renz \& Taub & LR(nt) \\
8 & Ophrys cilicica Schlechter & LR(lc) \\
9 & Ophrys holoserica (Burnm.fil) Greuter subsp. Heterochila Renz \& Taub & VU \\
10 & Ophrys isaura Renz \& Taub & EN \\
11 & Ophrys lycia Renz \& Taub & EN \\
12 & Ophrys phrygia Fleischm. \& Bornm. & LR(lc) \\
13 & Orchis reinholdii spruner ex Flischm. subsp leucotaenia Renz \&Taub & VU \\
14 & Ophrys transhyrcana Czernjak. subsp amanensis Nel. ex Renz \& Taub. & LR(cd)
\end{tabular}

\author{
verici, VU: Zarar Görebilir,
}


Çizelge 1. Kastamonu (Sezik ve Baykal 1991), Maraş (Sezik ve Baykal 1991), Muğla (Sezik 1967) ve Van (İşler 2005) Salebinin Elde edildiği Bölge ve Türlerin Dağılımı.

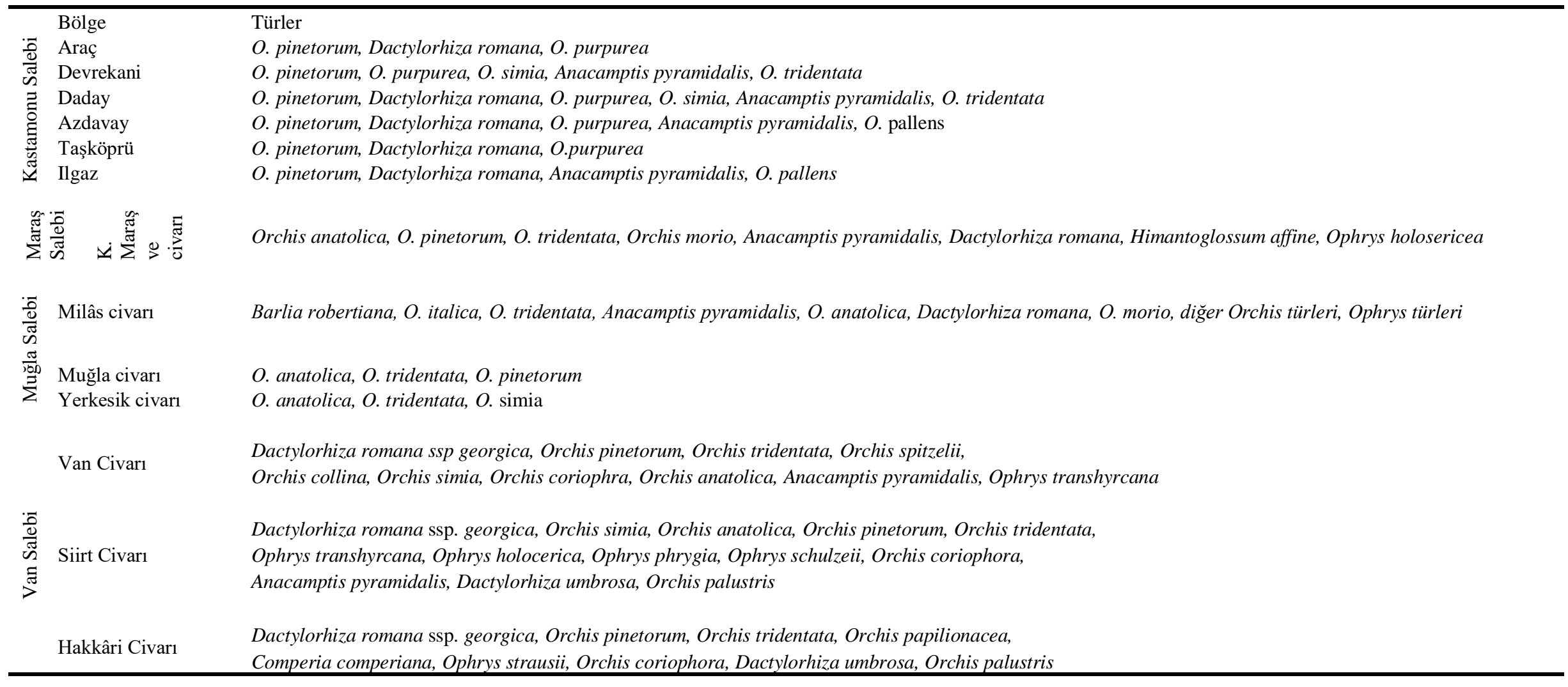


Ülkemizde 80 milyon civarında orkidenin salep elde edilmesi yüzünden tahrip olduğu, bu tahribin pek çok nadir ve endemik orkideyi de içine aldığı tespit edilmiştir (Çizelge 2). Salep elde edilişinin köylüye değil daha çok sayısı 10-15 civarında olan tüccara yarar sağladığı fiyat incelemeleri ile ortaya çıkmıştır. Diğer taraftan, salep kullanılmadan da dondurma ve sıcak sütlü içeceğin hazırlanabileceği, piyasada bunun örneklerinin bulunduğu gösterilmiştir (Sezik ve ark., 2007). Tekinşen ve ark. (2011) yaptıkları araştırmada, dondurma üretiminde konjak sakızından dondurma üretilebileceğini tespit etmişlerdir.

Salep elde edilmesinin yasaklanmasının hem tahribin durdurulmasında yaptırımının olduğu hem de imzaladığımız CITES anlaşması gereği olduğu tespit edilmiştir. Bunun yanında yasaklanma ile beraber alınması gerekli tedbirler de ayrıntılı bir şekilde incelenmiştir (Sezik ve ark., 2007).

\section{Materyal ve Yöntem}

Araştırma materyalini 2008-2010 yılları arasında üç vejetasyon döneminde (Nisan-Eylül) Muş ilinde (Şekil 1.) toplanan Orchidaceae familyası üyelerinin bitki örnekleri ile bu bitkilerin yumruları oluşturmaktadır.

\subsection{Araştırma alanının coğrafi durumu}

Bir Doğu Anadolu ili olan Muş 39²9've 38 $29^{\prime}$ kuzey enlemleri ile $41^{\circ} 06^{\prime}$ ve $41^{\circ} 47^{\prime}$ doğu

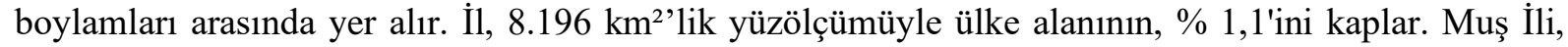
doğudan Ağrı'nın Patnos ve Tutak, Bitlis'in Ahlat ve Adilcevaz, kuzeyden Erzurum'un Karayazı, Hınıs ve Tekman, batıdan Bingöl'ün Karlıova ve Solhan, güneyden ise Diyarbakır'ın Kulp, Siirt'in Sason ve Bitlis'in Merkez ve Mutki, İlçeleriyle çevrilidir. Muş ilinin merkez dışında Malazgirt, Bulanık, Hasköy, Korkut ve Varto ilçeleri bulunmaktadır (Şekil 1.).Tarıma elverişli (\%97,5'i) olan il topraklarının yeryüzü şekillerine göre dağıtımında en büyük pay platolarındır (\% 37,9). Dağlar il alanının \% 34,9'unu kaplarken, ovaların payı \% 27,2 dir (Anonim, 1982-1984).

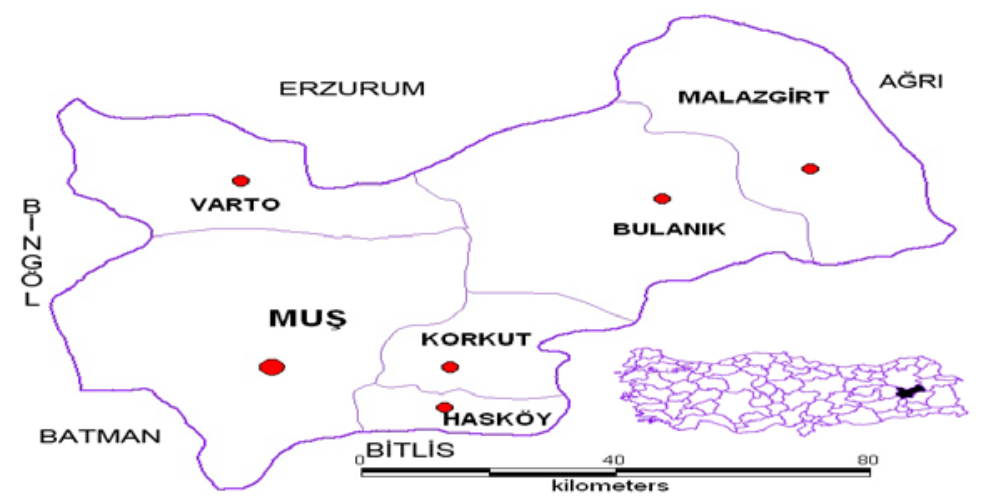

Şekil 1. Araştırma yöresinin coğrafi haritası.

\subsection{Numune Alma ve Saklama}

Arazi çalışmaları sırasında önce, bitkilerin teşhisine yardımcı olması için renkli fotoğrafları çekilmiş, toplanan bitkilerden herbaryum numunesi bilinen yöntemlerle hazırlanmıştır. Tayine yardımcı olmak üzere, bitkilerden alkol numunesi alınmıştır. Çalışmada Flora of Turkey' de yer alan türler ve isimlendirmeler esas olarak alınmıştır (Davis P. H. 1965-85). Bitkiler Van Yüzüncü Yıl Üniversitesi Herbaryumunda (VANF) saklanmaktadır.

\subsection{Salep ve Salep Ticareti}

Muş ilinde salep ticareti yapan insanların verdiği bilgiler doğrultusunda; köylülerden salebin nerelerde, nasıl ve hangi zaman dilimlerinde toplandığ 
alınmıştır. Bu bilgiler doğrultusunda; salep elde etmede kullandıkları orkide örnekleri belirlenen bölgelerden alınmış, salep elde etmede kullanılan türlerin teşhisi yapılmıştır. Salep ticareti ve köylülerden alınan bilgiler doğrultusunda salep çeşitleri ve ticareti hakkındaki genel bilgiler ortaya çıkarılmıştır.

\section{Bulgular}

Araştırmalarımız sonucu Muş civarında Dactylorhiza umbrosa, Dactylorhiza iberica, Anacamptis palustris, Orchis pseudolaxiflora, Anacamptis coriophora, Cephalanthera kotschyana ve Epipactis palustris türleri tespit edilmiştir. Bu türlerden yoğun olarak salep elde edildiği tespit edilmiştir. Bu bölüm salep, mahalli isimler başlıkları şeklinde sunulmuştur.

\subsection{Salep}

\subsubsection{Hasköy İlçesi -Altınova Beldesi civarı}

Belde ovaya kurulmuştur. Beldenin çıkış tarafinda üzeri seyrek meşelerle kaplı sıra dağlar bulunmaktadır. Beldenin seyrek olarak dağları kaplayan meşe ağaçlarının altında yumrulu orkidelere rastlanmazken çimenliklerde yumrulu orkidelere rastlanmıştır.

Orkideler çiçek açtığında veya yaprakları tanınabilir hale geldiğinde uzun yıllardan beri salep toplayıcıları tarafından yumrular toplanmaktadır. (Şekil 2A) Toplama işi, eni $5 \mathrm{~cm}$, boyu $10-15 \mathrm{~cm}$ ebatlarında demirden yapılmış ve bir metre boyunda bir sopanın ucuna geçirilmiş özel bir kazma ile yapılmaktadır (Şekil 2A).

Toplanan yumrular köye getirilir. Şayet hemen satılacaksa içi su dolu büyük bir leğen veya benzer kaplar içinde ovularak bir defa yıkanır. Tekrar leğene temiz su konur. Yumrular ikinci bir defa tekrar ovularak üzerlerinde bulunan çamurlardan kurtarılarak temizlenir. Yıkama esnasında su yüzeyine çıkan eski yumrular ve yabancı maddeler atılır. Temizlenen yumrular beldede bu işin ticaretini yapan iş yerlerine satılmaktadır. Eğer satılmayacaksa çamurlu haliyle satılacağı güne kadar bekletilmektedir (Şekil 2B). Satılıp satılmayacağını belirleyen günlük değişen fiyatlardır. Yerli bakkallar aldıkları salepleri haftalık olarak beldeye uğrayıp salep satın alan Siirt'li tüccarlara yaş olarak satılmaktadır. Siirt'li tüccarlar temizlenmiş yumruları büyük bir kazanın içerisine Koyarlar (Şekil 2C). Yumruların üzerine su doldurularak kaynatılır (Şekil 2D). Kaynatma işlemi peynir suyu ve süt ile de yapılabilir. Fakat genellikle kaynatma işlemi su ile yapılır. Su kaynamaya başlayınca bir süre beklenir, sonra kazanda bulunan yumrular süzgeçli kepçe ile süzülerek başka bir kaba alınır (Şekil 2E). Özel bir soğutma işlemine tabi tutulmadan güneş altına serilmiş çarşaf veya kilimler üzerine serilen yumrular güneş altında diş kesmeyecek hale gelene kadar kurutulur (Şekil 2F). Kurutulan salepler torbalar içerisine konularak bekletilir ve mevsim sonunda genellikle Siirt'li olan ve köye gelen alıcılar tarafindan satın alınarak Siirt'te veya büyük şehirlere gönderilir.

Belde de sadece çayır salebi bulunur. Çayırlıklardan elde edilenlere "Çayır malı, salebi " adı verilmektedir. Çayır salebi çatallı ve yuvarlak olmak üzere iki tip salepten oluşmaktadır. Ticarete genellikle karışık olarak çıkarılmaktadır. Beldede her yıl 4-8 ton salep toplanmaktadır. 2008 yılında çatallı salebin yaş kilogram fiyatı: 6 TL, 2009 ve 2010'da 8-10 TL, 2008 y1lında yuvarlak salebin yaş kilogram fiyat1: 12 TL, 2009 ve 2010'da 14 TL.'dir.

$\mathrm{Bu}$ bölgede Çayır salebi (malı) parçalı ve yuvarlak yumrulardan meydana gelmektedir. $\mathrm{Bu}$ karışımdaki parçalı yumrular Dactylorhiza umbrosa, Dactylorhiza iberica' a aittir. Yuvarlak olanlar ise Anacamptis palustris, Orchis pseudolaxiflora, Anacamptis coriophora türlerinin yumrularından meydana gelmektedir. 

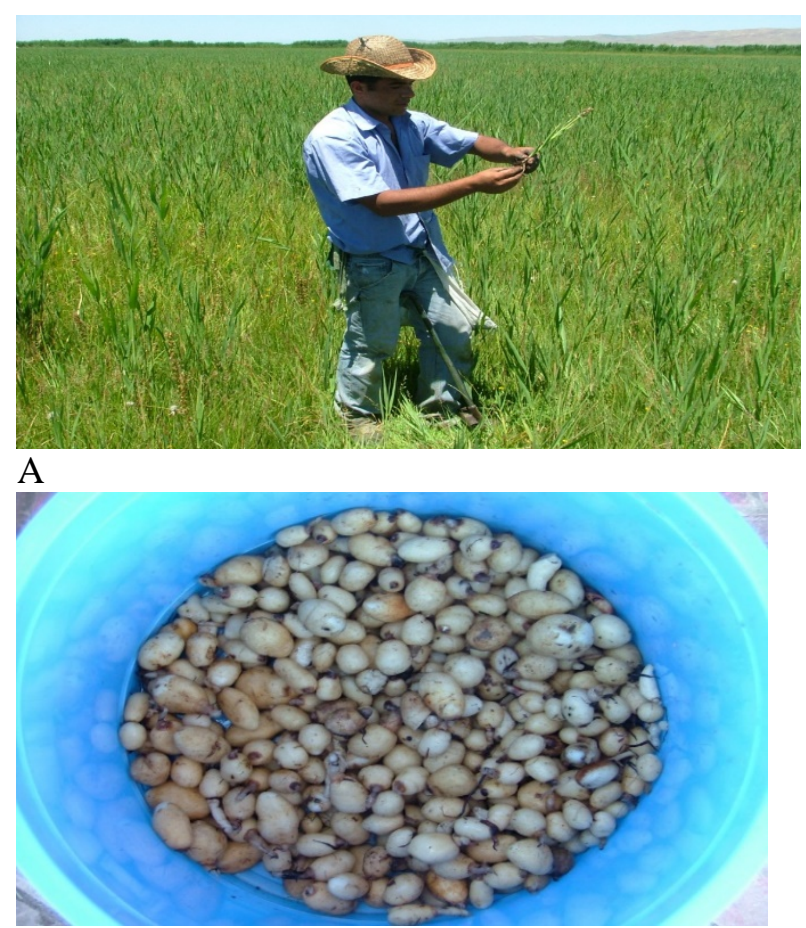

C

Şekil 2. a. Hasköy İlçesi -Altınova Beldesi civarı Salep elde edilişi A. Toplama B. Kirli yumrular C. Yıkanmış yumrular.

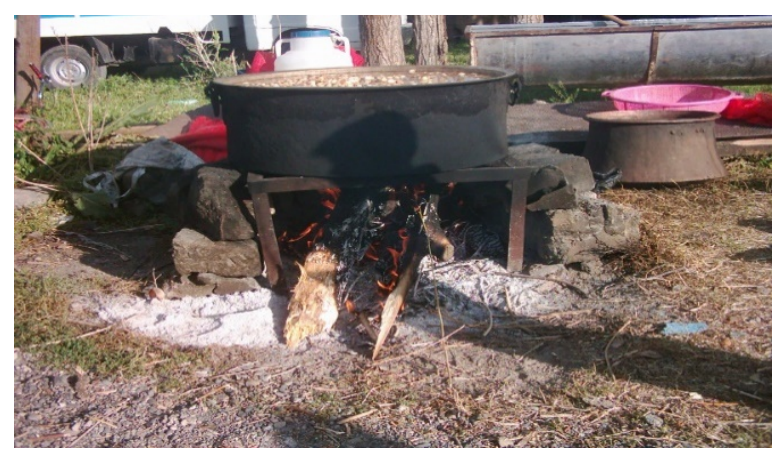

$\mathrm{D}$

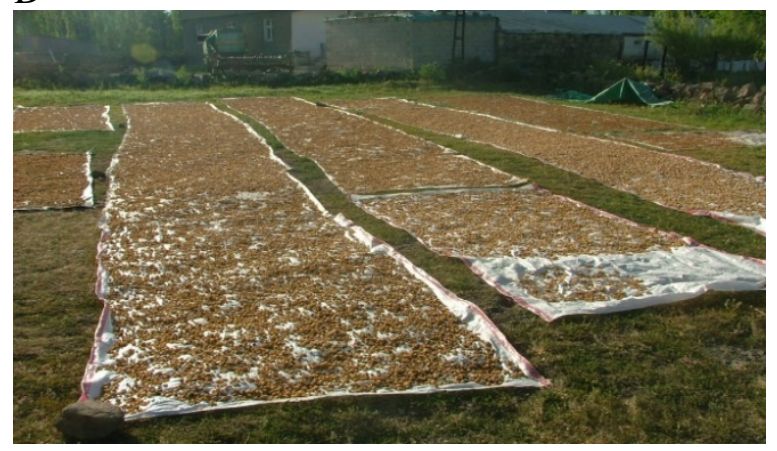

$\mathrm{F}$

Şekil 2. b. Hasköy İlçesi -Altınova Beldesi civarı Salep elde edilişi D. Kaynatma E. Kaynatmadan sonra F. Kurutma.

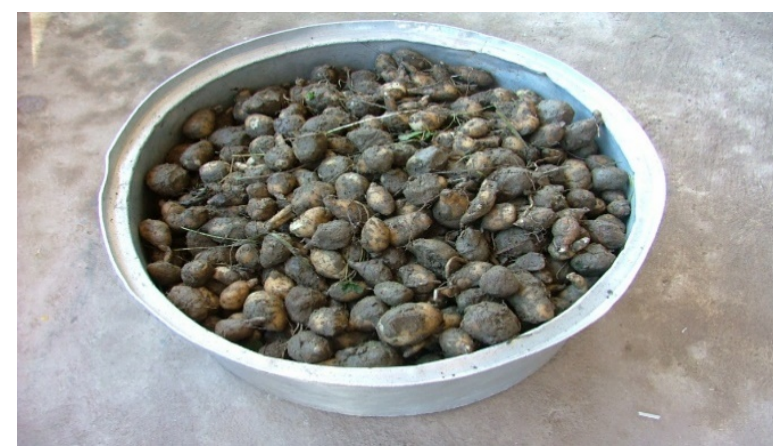

B

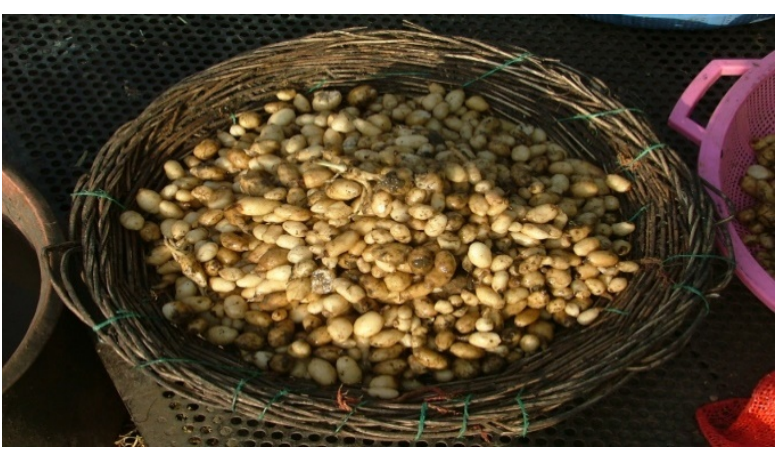

E 


\subsubsection{Bulanık İlçesi civarı}

İlçe dümdüz bir ovaya kurulmuştur. İlçenin güney tarafı üzeri seyrek meşelerle kaplı sıra dağlar bulunmaktadır. Beldenin seyrek olarak dağları kaplayan meşe ağaçlarının altında rizomlu orkidelere rastlanırken, çimenliklerde yumrulu orkidelere rastlanmaktadır.

Bu bölgede salep toplama işi bitkiler çiçek açtığında veya yaprakları tanınabilir hale geldiğinde uzun yıllardan beri işleri salep kazımak olan köyün gençleri ve çocukları ile Diyarbakır'dan sadece bu iş için gelen gençler tarafindan yapılmaktadır. Salep toplayıcıları özel kazmalarla yumruları toplamaktadır (Şekil 2A). Yumrulardan salep elde edilişi Altınova beldesindekine benzer şekilde yapılmaktadır (Şekil 3a,b). Kurutulan salepler torbalar içerisine konularak bekletilir. Mevsim sonunda ilçeye gelen ve genellikle Siirt'li olan alıcılar tarafından satın alınır ve Siirt veya büyük şehirlere gönderilir. İlçede sadece çayır salebi bulunur. Çayırlıklardan elde edilenlere "Çayır malı, salebi" adı verilmektedir. Çayır salebi çatallı ve yuvarlak olmak üzere iki tip salepten oluşmaktadır. Ticarete genellikle karışık olarak çıkarılmaktadır. İlçede her yıl 2-4 ton salep toplanmaktadır. 2008 yılında çatallı salebin yaş kilogram fiyatı: 6 TL, 2009 ve 2010'da 8-10 TL, 2008 yılında yuvarlak salebin yaş kilogram fiyatı: 12 TL, 2009 ve 2010'da 14 TL olmuştur.

$\mathrm{Bu}$ bölgede Çayır salebi (malı) parçalı ve yuvarlak yumrulardan meydana gelmektedir. $\mathrm{Bu}$ karışımdaki parçalı yumrular Dactylorhiza umbrosa, Dactylorhiza iberica'ya aittir. Yuvarlak olanlar ise Anacamptis palustris, Orchis pseudolaxiflora, Anacamptis coriophora türlerinin yumrularından meydana gelmektedir.

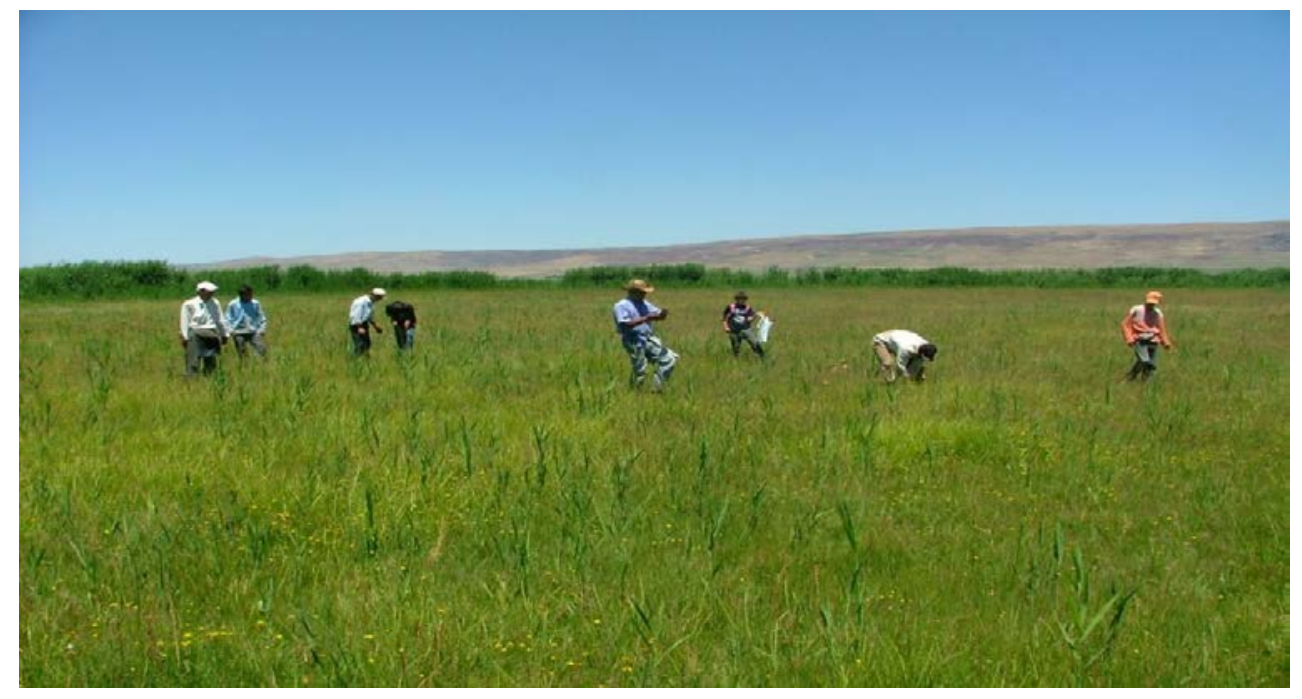

Şekil 3. Hasköy’de Salep toplayıcıları. 


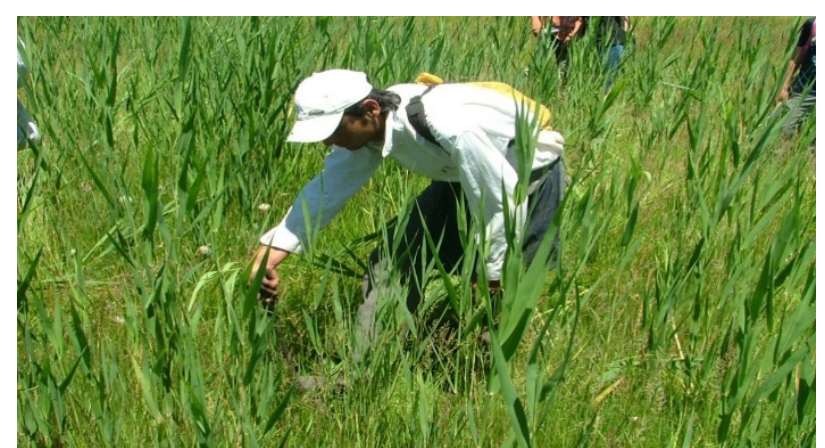

A

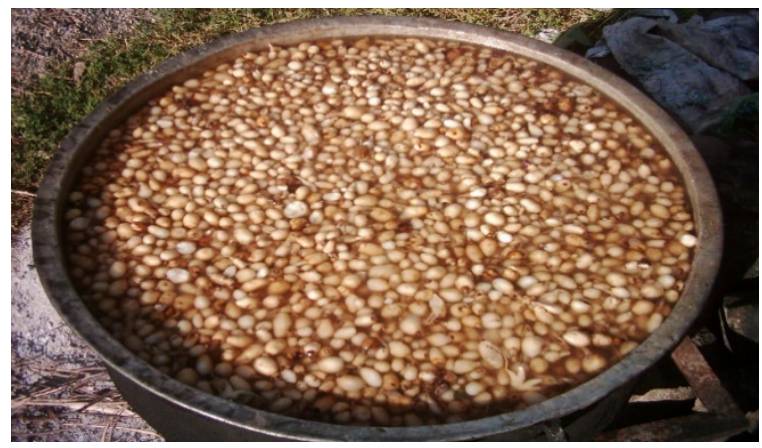

C

Şekil 3. a. Bulanık İlçesi civarı Salep Elde Edilişi A. Toplama B. Kirli Yumrular C. Yıkanan yumrular.

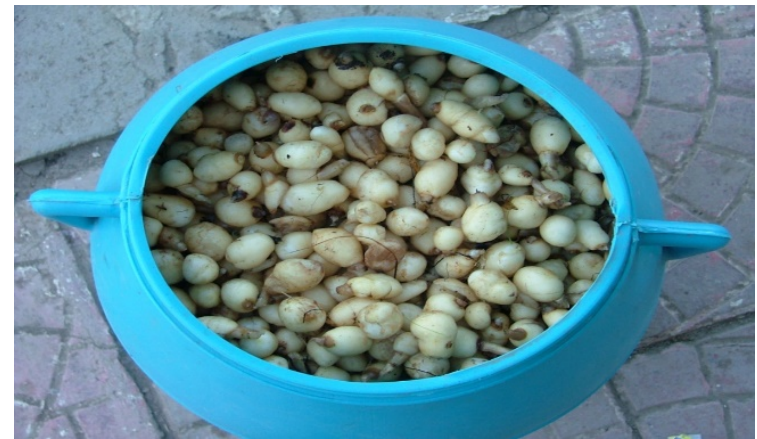

$\mathrm{D}$

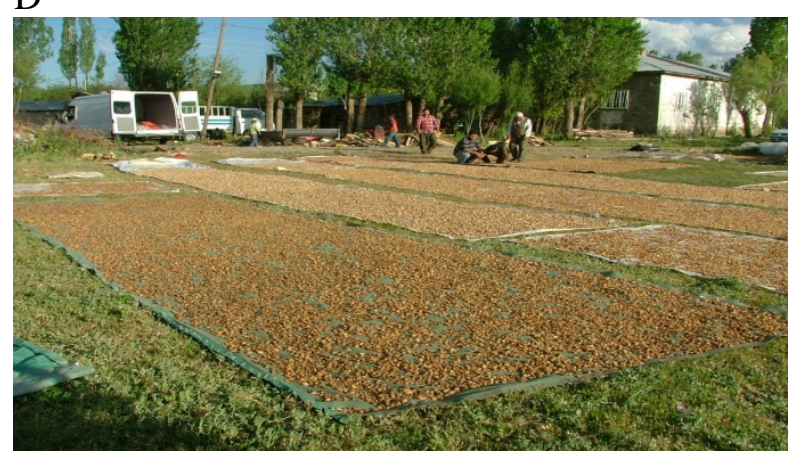

$\mathrm{F}$

Şekil 3. b. Bulanık İlçesi civarı Salep Elde Edilişi D. Yıkanan yumrular E. Kaynatma F. Kurutma.

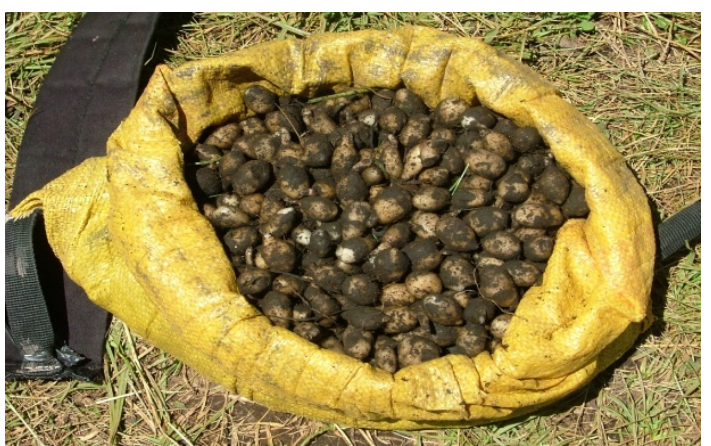

B

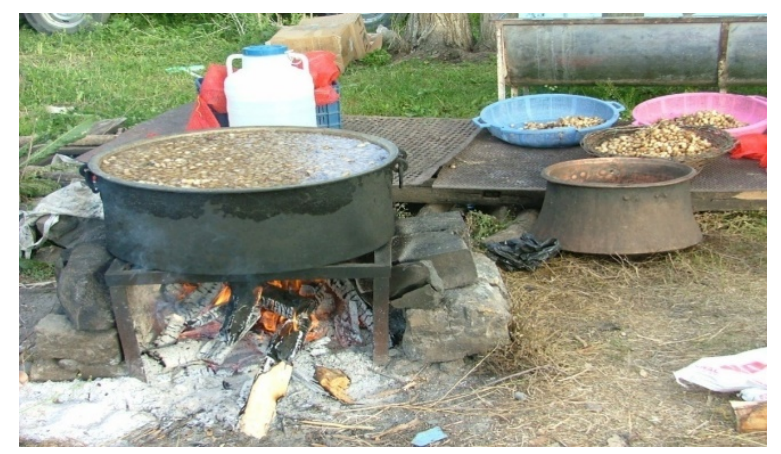

$\mathrm{E}$ 


\subsection{Ticari Salep Yumruları}

Salep ticaret merkezleri ve toplayıcılarından salep numuneleri de satın alınmış ve bu numunelerle ilgili bilgi ve resimler aşağıda sunulmaktadır (Şekil 4. a,b,).

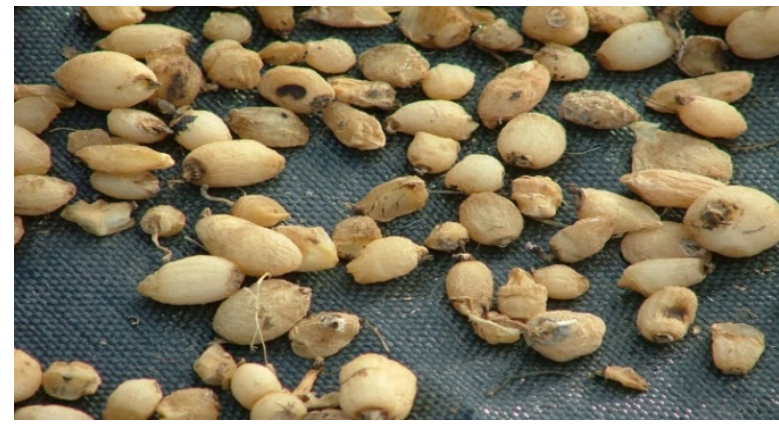

A

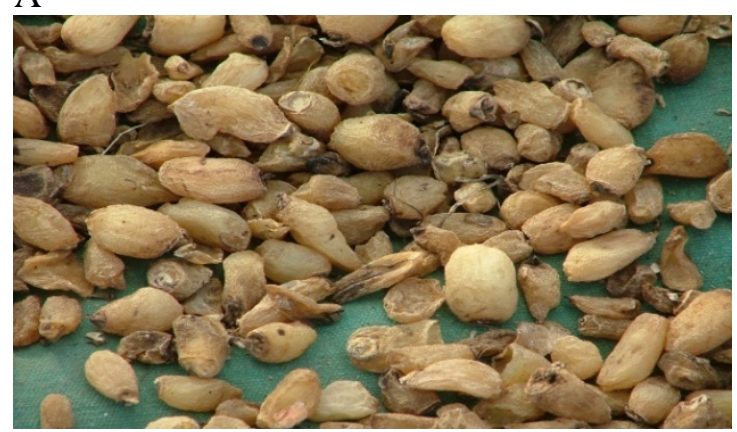

C

Şekil 4. a. Muş bölgesinde bulunan ticari salep resimleri A, B. C. Hasköy İlçesi -Altınova Beldesi.

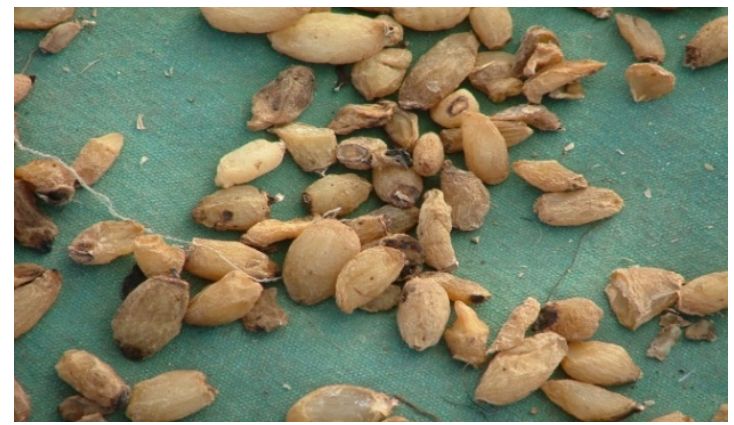

$\mathrm{D}$

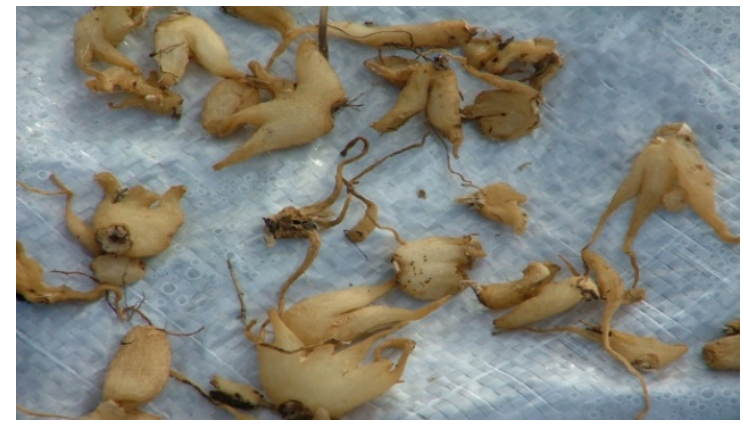

$\mathrm{F}$

Şekil 4. b. Muş bölgesinde bulunan ticari salep resimleri D. E, F. Bulanık ilçesi.

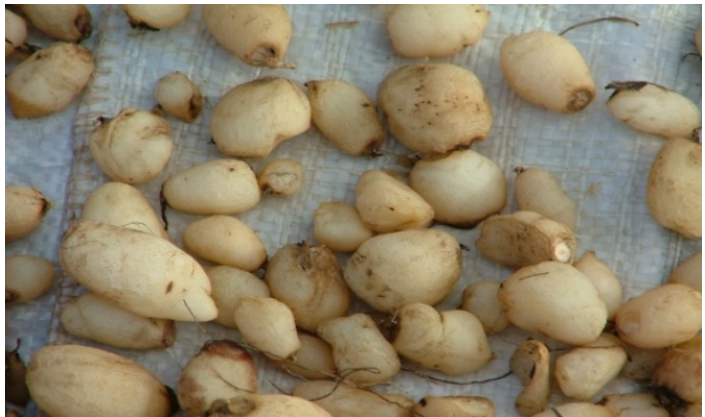

$\mathrm{E}$

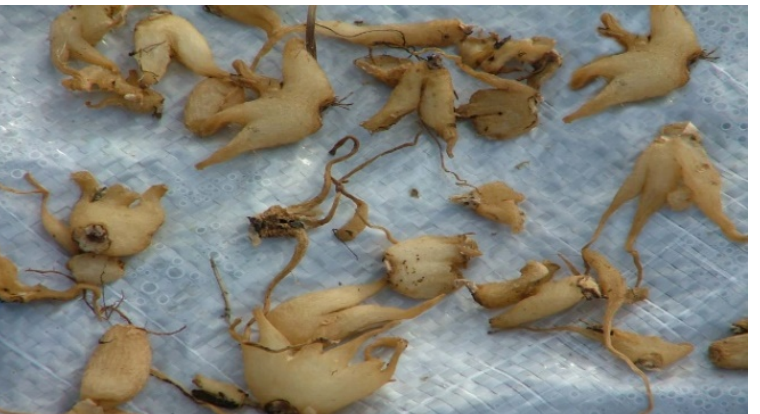

$\mathrm{B}$ 


\subsection{Muş bölgesinde salep için belirlenen mahalli isimler}

Bölgede salebe aşağıdaki mahalli isimler verilmektedir (çizelge 3).

Çizelge 3. Muş Bölgesinde salebin yerel isimleri.

\begin{tabular}{ll}
\hline Muş Merkez & hebhebuk \\
Malazgirt ilçesi & hebhebuk \\
Bulanık ilçesinde & hebhebuk \\
Varto ilçesi & piçuk \\
Hasköy ilçesi & hebhebuk \\
Korkut ilçesi & hebhebuk \\
\hline
\end{tabular}

\subsection{Muş civarı orkidelerinin Tehlike kategorileri}

Çalışma alanında bulunan orkidelerin tehlike kategorilerinin belirlenmesinde tabiatta bulunma sıklığının yanında salep elde edilişinde kullanılıp kullanılmadığı, diğer çevre faktörlerinin etkisi gibi kriterler göz önüne alınarak belirlenmiştir (Çizelge 4).

Çizelge 4. Muş civarı orkidelerinin tehlike kategorileri teşhis edilen türler.

\begin{tabular}{lc}
\hline Bitki Türü & Tehlike kategorileri \\
\hline Cephalanthera kotschyana Renz et Taub. & $\mathrm{LR}$ \\
Dactylorhiza iberica (Bieb. ex Willd.) Sóo & $\mathrm{Nt}$ \\
Dactylorhiza umbrosa (Kar. et Kir.) Sóo & $\mathrm{Ic}$ \\
Epipactis palustris (L.) Crantz & $\mathrm{LR}$ \\
Anacamptis coriophora L. & $\mathrm{VU}$ \\
Anacamptis palustris Jacq. & $\mathrm{VU}$ \\
Orchis pseudolaxiflora Czerniakovska & $\mathrm{VU}$ \\
\hline
\end{tabular}

LR: Az Tehdit Altında, nt: Tehdit Altına Girebilir, lc: En az endişe verici, VU: Zarar Görebilir,

\section{Tartışma ve Sonuç}

Çalışmamız sonucunda Muş salebinin elde ediliși, ticareti, elde etmede kullanılan orkidelerin hangileri olduğu tespit edilmiştir. Muş salebi hakkındaki ilk bilginin Sezik tarafından 1967 tarihli olduğu düşünülürse, çalışmamızın önemli bir eksikliği giderdiği ortaya çıkmaktadır.

Araştırmalarımız sırasında, Diyarbakır‘da da salep toplandığı tespit edilmiştir. Bu da yeni ve önemli bir bilgidir.

Muş İlinde 4 cinse ait 7 orkide türü bulunduğu da araştırmamız sonucu tespit edilmiştir. $\mathrm{Bu}$ türlerden önemli bir kısmına ait herbaryum örnekleri, ve resimleri elde edilmiş ve bölgemizdeki türlere ait taksonomik özellikler tespit edilmiştir. Bazı türlere (Cephalanthera kotschyana), bölgedeki güvenlik sorunları dolayısıyla çok zor ulaşılmıştır. Ama Muş çevresi orkidelerine ait önemli bir bilgi birikimi sağlanmıştır Bu bilgi birikimi palustris grubu orkidelerin incelenmesi gibi, daha ileri çalışmalarında yapılmasını sağlayacaktır.

Çalışmamız Muş bölgesinde yaklaşık 40-50 yıldır salep toplandığını, salep üretiminin arttı̆̆ını da ortaya çıkarmıştır. Özellikle çayırlık arazide yetişen orkideler hızla tüketilmektedir. Dolayısıyla, önemli bir çevre sorunu, tabiat tahribi de söz konusudur. Bu konu da ihmal edilmemelidir.

Ayrıca aşırı salep sökümü, aşırı otlatma, tarım, kentleşme, ormancılık, endüstrileşme, orman yangınları, su kaynaklarına dönük projeler ve salep toplayıcıların ekonomik durumları 28 türü endemik olan orkidelerin giderek yok olmasına sebep olmaktadır. 
Muş Salebi hakkındaki ilk veri Sezik’ in 1967 yılındaki çalışmasında Van salebi başlığı altındaki bilgilere dayanmaktadır. Bu çalışmadan sonra, Muş salebi hakkında değişik kaynaklardaki bilgilerin hepsi yukarıda belirtilen çalışmadan alınmıştır. Bu bilgiler de bölgenin tarifi, salebin taşıdığı müsilaj, nişasta, serbest ve bağlı oz miktarları, saleplerin ortalama ağırlıklarından ibarettir. Çalışmamız sonucunda, Muş salebinin ticareti, çeşitleri, bu çeşitlerin elde ediliş yöntemleri, elde edilişinde kullanılan orkidelerin hangileri olduğu, salebin morfolojik özellikleri tespit edilmiştir. Bütün bu bilgiler hakkında çok sayıda görsel materyal de elde edilmiştir.

Muş salebinin elde edilişinde kullanılan orkideler, diğer bölgelerle karşılaştırıldığında şu sonuçlar ortaya çıkmaktadır:

- A. coriophora, bütün bölgelerde salep elde edilişinde kullanılmaktadır.

- Çayır salebi elde edilişinde, A. palustris, O. pseudolaxiflora, Dactylorchiza umbrosa, Dactylorhiza iberica türleri kullanılmaktadır.

- Muş salebinin ticaret merkezinin Siirt olarak değiştiği bu çalışma sonucunda ortaya çıkmıştır. Hatta piyasada bazı bölgelerde Doğu malı artık Siirt salebi olarak kabul edilmektedir.

Çalışmamız Muş salebinin Doğu salebi veya Siirt salebi diye isimlendirilmesinin daha doğru olacağını ortaya çıkarmıştır.

Araştırmalarımız sırasında, Diyarbakır'da da salep toplandığı bilgisine ulaşılmış, fakat Diyarbakır'da salebin nerelerden toplandığı şu an için tespit edilememiştir. Bu konu ayrı bir araştırmayı gerektirmektedir.

Muş Bölgesinde hangi orkidelerin bulunduğu hem literatür hem de arazi çalışmaları sonucu ortaya çıkarılmıştır.

Araştırma bölgemizde tespit edilen Anacamptis palustris, Orchis pseudolaxiflora bölgede bulunan ve birbirine benzeyen 2 türdür. Bu türlerin genel özelliklerine benzeyen türler bulunmuş ve ayrı ayrı belirtilmiştir. Ama her ikisine de benzeyen türler de görülmüştür. Dolayısıyla çalışmamız, ileride yeni bir çalışmanın daha yapılması gereğini ortaya çıkarmıştır. Sulak alanlardaki palustris grubu orkideler ayrı bir çalışma halinde İncelenmelidir.

Cephalantera türleri bölgemizde seyrek ve az olarak bulunmaktadır. Daha önce bulduğumuz lokalitelere tekrar gidildiğinde bazen bulmak mümkün olmamıştır.

Arazi çalışmalarımız esnasında orkidelerin habitatı, bulunma sıklığı not edilmiştir. Bu bilgilere göre Dactylorhiza umbrosa, Anacamptis palustris veya Orchis pseudolaxiflora ile beraber sulak alanlarda geniş topluluklar meydana getirmektedir. Bu topluluklarda bazen Dactylorhiza iberica da katılmaktadir.

Anacamptis coriophora da taban suyu bol olan alanlarda yalnız veya Dactylorchiza türleri ile beraber bulunmaktadır.

Bölgede hakim ağaçlıklar, meşeliklerdir. Endemik bir tür olan Cephalanthera kotschyana meşeliklerde bulunmaktadır. Diğer yumrulu orkideler de çayırlıklarda yaşamaktadırlar. Genellikle birkaç türü bir arada bulmak mümkündür. Ayrıca bazı türler yoğun bir populasyona sahip iken, bazı populasyonlar seyrektir. Salep kazıldığı için eskisinden daha seyrek bulunduğu köylüler tarafından ifade edilmektedir.

Yukarıda belirtilen orkide tahribatını engellemek için; Tarım ve Orman İl Müdürlükleri, Özel idareler ve Sivil toplum kuruluşları tarafindan yerinde koruma (in situ) veya habitat dışında koruma (ex situ) yönelik projelerle halkın kültürel, sosyal ve ekonomik olarak bilinçlendirilmesi gerekmektedir.

Ayrıca salep ve dondurma yapımı için orkidelerin yumrularının yerine alternatif olarak konjak sakızı kullanılabilir.

Bölgede bulunan orkideler için Bulgular kısmında tehlike kategorileri de verilmiştir. Çünkü salep elde edilişi bu hızla giderse bölgedeki orkideler hızla bir şekilde yok olacaktır. Muş civarında Anacamptis palustris, Anacamptis coriophora, Dactylorhiza umbrosa, Dactylorhiza iberica ve Orchis pseudolaxiflora türlerine ait kayıtlar, salep elde edilişi bu hızla giderse, tarihi birer kayıt olarak yayınlarda, örnekleri ise herbaryumlarda bulunacaktır. 


\section{Teşekkür}

$\mathrm{Bu}$ konuda çalışırken bana araştırmanın başlangıcından sonuna kadar araştırmamızı maddi açıdan destekleyen (2008-FED-B086) Yüzüncü Y1l Üniversitesi Araştırma Fonu Başkanlığına teşekkür ederim.

\section{Kaynakça}

Anonim, (1982-1984). Yurt Ansiklopedisi, Cilt: 10, Anadolu yayınc1lık. 7531-7589.

Baytop, T. (1968). Çayır Salebinin Menşei. İstanbul Ecz. Fak. Mec., 4, 69.

Baytop, T., \& Sezik, E. (1968a). Türk Salep Çeşitleri Üzerinde Araştırmalar. İstanbul Ecz. Fak. Mec., 4, 61.

Davis, P. H. (1965-85). Flora of Turkey and The East Aegean Islands. Vol. 1-9, Edinburg Univ. Press., Edinburg.

Ekim, T., Koyuncu, M., Vural, M., Duman, H., Aytaç, Z., \& Adıgüzel, N. (2000). Türkiye Bitkileri Kırmızı Kitabı, Yayın no: 18, Ankara.

Erdem, H. E. (2004). Biyolojik çeşitliliğin ekonomik değerinin belirlenmesi: yabani orkide örneği. Ege Üniv. Fen Bilimleri Enst. (Yüksek Lisans Tezi). Çevre Bilimleri Ana Bilim Dalı. BornovaIZMIR S.99.

Geylan, A. (2017). Hakkâri çevresi'nde Orchıs Sp. (Orchidaceae) türlerinin vejetatiforganları üzerinde anatomik araştırmalar. Eğitim Bilimleri Enstitüsü Yüksek Lisans Tezi (Basılmamış), Van.

İşler, S. (2005). Van salebinin menşei ve Van civarının orkideleri. Fen Bilimleri Enstitüsü Doktora tezi (Basılmamış), Van.

Kreutz, C.A.J. (1998). Die Orchideen der Türkei. Cip-Gegevens Koninklijke Bibliotheek, Den Haag. 650.

Kreutz, C. A. J. (2000). Orchidaceae Flora of Turkey and East Egean Islands, V.Il (A. Güner, Özhatay, N., Ekim, T., Başer, K.H.C., Published by. University Press, Edinburg, 656.

Petrou, N., Petrou, M., Deniz, İ G., Sezik E., Georgiadis, C. \& Getsos, M. (2016). Greek-Turkish White Paper, Antalya.

Renz, J., \& Taubenheim, G. (1984). Orchidaceae Flora of Turkey and East Aegean Islands, V.8 (P.H. Davis, R. Mill, K. Tan, eds.), Published by University Press, Edinburgh, 632.

Schlechter, R., 1928. Monographie und Iconographie der Orchideen Europas und des Mittelmeergebietes, 1, Repert. Specierum nov. Rengi Vegetabilis, sonderbeiheft A.

Sezik, E. (1967). Türkiyenin salepgilleri ticari salep çeşitleri ve özellikle Muğla salebi üzerinde araştırmalar. İst. Üniv., Eczac1lık Fak., Doktora Tezi, No. 34, İstanbul.

Sezik, E. (1969a). Muğla salebinin menşei ve kalitesi. TÜBİTAK 2. Bilim Kong. Tbl. Tıp, 8.

Sezik, E. (1984). Orkidelerimiz. Sandoz Kültür Yayınları, İstanbul, 166.

Sezik, E. (1982). Türkiye’de Orchidaceae familyası. IV. Bitkisel İlaç Hammaddeleri Topl. Tebliğleri, Eskişehir.

Sezik, E (2002a). Türkiye’nin orkideleri ve salep. Acta Pharmaceutica Turcica, 44, 151-157.

Sezik, E. (2002b). Destruction and conservation of Turkish orchids. In Biodiversity (pp. 391-400). Springer, Boston, MA.

Sezik, E., \& Baykal, T. (1991). Maraş salebinin menşei. Doğa-Tr. J. of Pharmacy, 1, 10.

Sezik, E., \& Baykal, T. (1988). Maraş Salebinin Menşei ve Maraş Civarının Orkideleri. TÜBİTAK Projesi, TBAG-664, Ankara.

Sezik, E., İşler, S., Güler, N., Orhan, Ç., Aybeke, M., Deniz, İ. G., \& Üstün, O. (2007). 'Salep ve Orkidelerin tahribi' Tübitak Projesi TBAG-Ç.SEK/23(103T008), Ankara.

Sezik, E., \& Özer, YB. (1983). Kastamonu Salebi'nin menşei ve Kastamonu Civarının Orkideleri. TÜBİTAK projesi, TBAG-424, Ankara.

Stevens, PF. (2008). 'Angiosperm Phylogeny website version 9'. Missouri Botanical Garden. Retrieved 26 May 2013.

Tekinşen, K. K., Güner, A., \& Uçar, G. (2011). Dondurma üretiminde konjak sakızının kullanılabilme imkânları. Eurasian Journal of Veterınary Science, 27, 4, 199-206. 